\title{
Examining the Climatology of Shortwave Radiation in the Northeastern United States 0
}

\author{
JANEl HanRahan AND AleXANDria MAYNARD \\ Lyndon State College, Department of Atmospheric Sciences, Lyndonville, Vermont
}

\author{
SARAH Y. MURPHY
}

Washington State University, Department of Civil and Environmental Engineering, Pullman, Washington

\author{
COLTON ZERCHER AND ALLISON FITZPATRICK
}

Lyndon State College, Department of Atmospheric Sciences, Lyndonville, Vermont

(Manuscript received 30 December 2016, in final form 4 August 2017)

\begin{abstract}
As demand for renewable energy grows, so does the need for an improved understanding of renewable energy sources. Paradoxically, the climate change mitigation strategy of fossil fuel divestment is in itself subject to shifts in weather patterns resulting from climate change. This is particularly true with solar power, which depends on local cloud cover. However, because observed shortwave radiation data usually span a decade or less, persistent long-term trends may not be identified. A simple linear regression model is created here using diurnal temperature range (DTR) during 2002-15 as a predictor variable to estimate long-term shortwave radiation (SR) values in the northeastern United States. Using an extended DTR dataset, SR values are computed for 1956-2015. Statistically significant decreases in shortwave radiation are identified that are dominated by changes during the summer months. Because this coincides with the season of greatest insolation and the highest potential for energy production, financial implications may be large for the solar energy industry if such trends persist into the future.
\end{abstract}

\section{Introduction}

Observed increases in atmospheric greenhouse gases, particularly carbon dioxide, are largely attributed to global energy use that depends on the combustion of fossil fuels (Canadell et al. 2007; Le Quéré et al. 2009; Andres et al. 2012). To mitigate this and resulting global climate changes moving forward, an increasing portion of this energy must come from renewable sources (IPCC 2011). There are currently 29 U.S. states with goals of obtaining most or all of their energy from renewable sources within the next few decades (Durkay 2016). Some of the most aggressive renewable energy goals

Supplemental information related to this paper is available at the Journals Online website: https://doi.org/10.1175/ JAMC-D-16-0420.s1.

Corresponding author: Janel Hanrahan, janel.hanrahan@ lyndonstate.edu have been identified by states in the Northeast, including Rhode Island ( $15 \%$ by 2019$)$, Massachusetts $(15 \%$ by 2020), New Hampshire (25\% by 2025), Connecticut ( $27 \%$ by 2020 ), Maine ( $40 \%$ by 2017$)$, New York $(50 \%$ by 2030 ), and Vermont ( $75 \%$ by 2032 ). While this renewable energy can come from a variety of sources, it is projected that many of the long-term needs are likely to be met with solar power, which is expected to expand on a massive scale (Shmalensee et al. 2015) largely driven by the installation of utility-scale solar power plants (Honeyman et al. 2016).

Cited as a key risk with large-scale solar photovoltaic (PV) projects, incorrect estimations of energy production due to unanticipated weather patterns can have large impacts on long-term revenue [International Finance Corporation (IFC) 2014]. Solar radiation, in particular, can vary on decadal and multidecadal time scales (Wild 2012; Zhang et al. 2015), greatly impacting PV energy production (Jones and Underwood 2001). Such changes may be associated with large-scale climate 

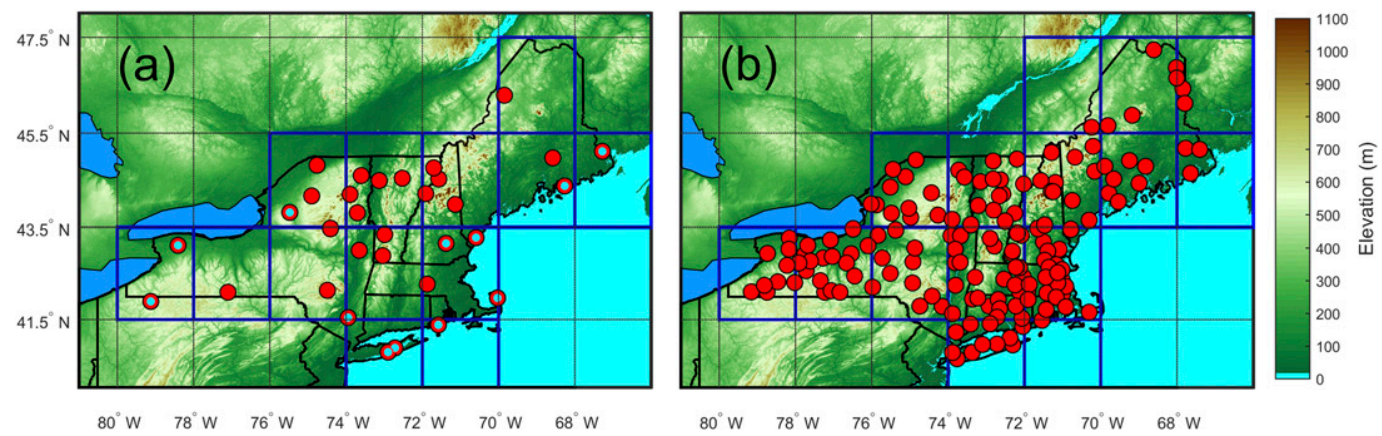

FIG. 1. Individual locations (red circles) and area-averaged regions (blue boxes) for (a) both hourly temperature and SR (see Table S1 in the online supplemental material for station details) and (b) only hourly temperature. Light-blue concentric circles in (a) indicate stations within $80 \mathrm{~km}$ of large bodies of water as discussed in section 4a. Data were obtained from MesoWest (Horel et al. 2002).

variability, which modifies long-term cloud cover (Dai et al. 1999, 2006; Dim et al. 2011; Eastman and Warren 2013). An observed long-term increase in annual precipitation in the northeastern United States (Lauritsen and Rogers 2012; Peterson et al. 2013; Tang and Leng 2013) is linked to a substantial decline in surface shortwave radiation through increasing frequency of overcast skies and modified cloud properties (Dai et al. 1999; Liepert 2002; Stone and Weaver 2003). Modeling studies suggest that such trends will continue in this region under various climate change scenarios (Walsh et al. 2014). In spite of this, expected energy output at proposed PV plant sites is estimated from observed shortwave radiation data that usually span $10 \mathrm{yr}$ or less. Such data may not adequately capture long-term trends and variability, but the plant itself may have a lifetime in excess of several decades (IFC 2014).

To identify long-term trends and variability of potential solar energy production in the northeastern United States, an extended climatology of shortwave radiation is needed. The goals of this work are as follows: 1) identify an alternative method for creating a climatology of shortwave radiation in the Northeast and 2) identify long-term changes in shortwave radiation based on this new climatology. A shortwave radiation (SR) climatology is created here using methods similar to those identified by Betts et al. $(2013,2014)$ and Betts and Tawfik (2016); they used a unique long-term hourly cloud cover dataset to show that the magnitude of diurnal temperature range (DTR) is strongly dependent on the fraction of opaque cloud cover in the Canadian Prairies, which in turn is directly related to the shortwave albedo of the cloud field (Betts et al. 2015). Because of differences in radiative forcing, clear skies are linked to large DTR values and overcast skies are linked to small DTR values (Fig. 3.22 in Ahrens 2013), thus providing valuable information about SR when direct observations are not available.
To maintain a focus on long-term climatological shifts in SR due to increasing anthropogenic greenhouse gases, we investigate recent successive 30-yr climatological periods, $\mathrm{SR}_{1}$ : 1956-85 and $\mathrm{SR}_{2}$ : 1986-2015. These durations were chosen to filter out near-decadal periodicities in regional moisture that may be associated with natural climate modes such as the North Atlantic Oscillation (Moron et al. 1998; Da Costa and De Verdiere 2002; Hanrahan et al. 2009, 2014).

In section 2, we quantify the relationship between SR and DTR for the northeastern United States during individual months and over the entire year. A probabilistic linear regression model is then identified in section 3 that is used to estimate SR during 1956-2015. Also presented in this section is a detailed analysis of climatological changes over time. In section 4 , we discuss the potential for limitations of this work as they pertain to regional influences and temporal shifts, and we provide a summary and major conclusions in section 5 .

\section{Quantifying a relationship between diurnal temperature range and shortwave radiation}

\section{a. Data}

To establish a relationship between DTR and SR, hourly temperature $\left({ }^{\circ} \mathrm{C}\right)$ and incoming shortwave radiation $\left(\mathrm{W} \mathrm{m}^{-2}\right)$ data were obtained from the U.S. weather observation database MesoWest (Horel et al. 2002) for the northeastern United States. Suitable locations included at least four years of data for both DTR and SR during concurrent time periods extending through the end of 2015 (start times vary). All data were inspected for quality and questionable values were removed (i.e., DTR or SR of zero for several days in a row or unrealistically large values). Months with fewer than 20 days of data were not considered. The resulting dataset of DTR and SR values included 32 stations around the region (Fig. 1a; red circles) with 
TABLE 1. Correlation and linear regression values between DTR and SR across all grid cells (blue circles in Fig. 2).

\begin{tabular}{lcccccrr}
\hline \hline & $n$ & $r$ & $r^{2}$ & Slope $s$ & $y$ intercept $b\left(\mathrm{~W} \mathrm{~m}^{-2}\right)$ & $\overline{\mathrm{SR}}\left(\mathrm{W} \mathrm{m}^{-2}\right)$ & ${\text { Std dev of residual } \varepsilon\left(\mathrm{W} \mathrm{m}{ }^{-2}\right.}^{2}$ \\
\hline Jan & 4394 & 0.22 & 0.05 & 1.63 & 37.40 & 54.36 & 33.57 \\
Feb & 3937 & 0.31 & 0.09 & 3.13 & 55.24 & 89.88 & 47.40 \\
Mar & 4238 & 0.51 & 0.26 & 7.17 & 60.39 & 144.09 & 63.35 \\
Apr & 4430 & 0.68 & 0.46 & 11.46 & 44.77 & 187.93 & 67.44 \\
May & 4555 & 0.74 & 0.55 & 13.38 & 43.43 & 216.00 & 63.63 \\
Jun & 4599 & 0.76 & 0.57 & 15.41 & 39.73 & 224.88 & 59.86 \\
Jul & 4824 & 0.68 & 0.46 & 14.30 & 60.26 & 235.83 & 57.69 \\
Aug & 4970 & 0.69 & 0.47 & 13.01 & 48.11 & 208.84 & 51.87 \\
Sep & 4895 & 0.69 & 0.47 & 10.76 & 31.34 & 165.58 & 49.21 \\
Oct & 5111 & 0.68 & 0.46 & 7.93 & 16.61 & 65.53 & 38.90 \\
Nov & 4842 & 0.51 & 0.26 & 4.59 & 20.42 & 41.85 & 31.51 \\
Dec & 5028 & 0.29 & 0.09 & 1.99 & 24.37 & 26.16 \\
\hline
\end{tabular}

data for at least 29 locations during each individual month of the year (individual station names and information can be found in Table S1 in the online supplemental material).

Because of an uneven distribution of stations across the Northeast, we binned daily station SR and DTR data into $2.5^{\circ}$ latitude and longitude regions and computed spatial averages, resulting in 13 grid cells over the region (Fig. 1a; blue boxes). This was done to avoid disproportionately large influences by areas with high concentrations of data. For some grid cells, data from only one station were available, so no spatial averaging was necessary. For other grid cells, data for up to five stations were available with varying temporal coverage, so averages were computed using station data as available for each day.

Starting years for each grid cell range between 2002 and 2004 and data for all grid cells end in 2015. The average sample size for each month is $n=4652$ with a minimum of $n=3937$ (Table 1), where $n$ is defined as the total number of days multiplied by the number of grid cells with available data during each month. The regression analysis discussed below was performed on these area-averaged gridded data consisting of one value each of SR and DTR per day, per grid cell.

\section{b. Correlation between diurnal temperature range and shortwave radiation}

We computed correlation coefficients between daily gridded DTR and SR values for all months of the year. This was first done for each of the 13 grid cells independently (Fig. 2a; red times signs) and then repeated using data across all grid cells, resulting in a single correlation value for the entire Northeast per each month (blue circles). Lines of best fit were computed with DTR as the predictor and SR as the predictand. The resulting slopes are illustrated in Fig. $2 \mathrm{~b}$ for each grid cell (red X's) and across all grid cells (blue circles).

In agreement with Betts and Tawfik (2016) and Jackson and Forster (2010), we find that DTR is well
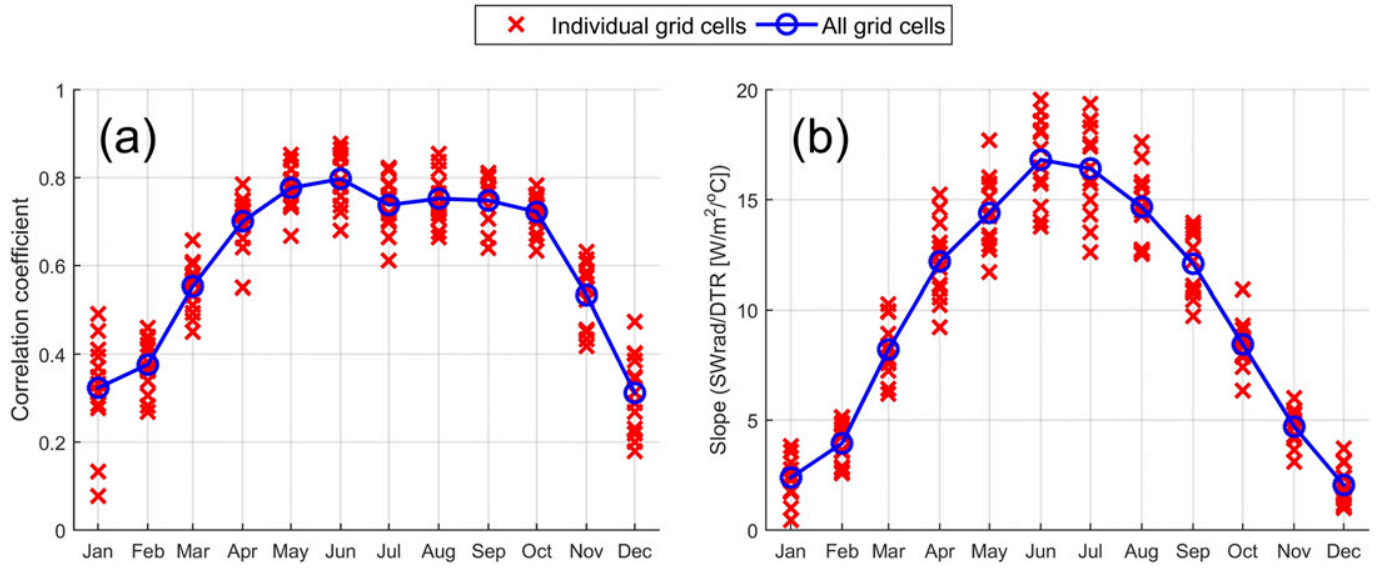

FIG. 2. (a) Correlation coefficients and (b) slopes of best-fit lines between daily diurnal temperature range (predictor) and daily averaged downward shortwave radiation (predictand) for each grid cell (red times signs; regions identified by blue boxes in Fig. 1) and across all grid cells (blue circles). 
correlated with SR throughout the year. Correlations for the entire region (across all grid cells) are statistically significant at the $99 \%$ confidence level during all months. The highest correlations occur during the warm season when shortwave radiation forcing dominates daily changes in temperature (Betts and Tawfik 2016). During April-October, average monthly correlations $r \geq 0.68$, indicating that at least $46 \%$ of incoming shortwave radiation may be explained by daily temperature ranges alone. Correlation coefficients during other months are also statistically significant, but the amount of shortwave radiation variability explained by DTR is lower. We find that the slope of the best-fit line (SR-DTR) is also maximized during June and minimized in January and December. This suggests that the same change in daily solar energy input triggers a small DTR response during the summer and a relatively large DTR response during the winter. Correlation values, however, are substantially smaller during the latter.

From this analysis, we conclude that DTR data for the northeastern United States can serve as a reliable proxy from which a climatology of shortwave radiation can be created, particularly during the warm season. The spatial variability in correlation $r$ and slope $s$ values as computed for individual grid cells is relatively low; most individual gridcell values (Fig. 2; red $\times$ 's) are within $25 \%$ of those computed for the entire region (blue circles). We thus focus on values representative of the entire Northeast (across all grid cells) hereafter. However, because the slope $s$ and standard error are largely dependent on time of year, unique functions were identified for each month.

\section{Climatology of shortwave radiation}

\section{a. Computing shortwave radiation from diurnal temperature range}

Daily area-average SR values $\left(\mathrm{W} \mathrm{m}^{-2}\right)$ can be computed using simple linear regression with DTR $\left({ }^{\circ} \mathrm{C}\right)$ as the predictor variable,

$$
\mathrm{SR}=s_{m} \times \mathrm{DTR}+b_{m}+\varepsilon_{m},
$$

where slope $s$ and $y$ intercept $b$ were obtained from the observed relationships for each month $m$ over the entire region (Table 1). For each day, the equation was solved 1000 times, with random error $\varepsilon$ drawn from the observed residual distribution about the least squared regression line.

To assess model performance, SR was first computed using (1) during 2002-15 with DTR data from the original 32 stations (Fig. 1a) after they were binned and spatially averaged (blue boxes). All solutions for each month are illustrated in Fig. 3 (thin gray lines). Average SR values were then computed for each of the 1000 realizations and sorted from smallest to largest. The 25th and 975th values (thick gray lines) represent the $95 \%$ range about the long-term average solution for (1). Observed daily SR values, as defined in section 2, were averaged by month (thin red lines) and over all years of available data (dashed red line). Monthly averages of observed SR are also quantified in Table 1.

In agreement with monthly correlations identified in the previous section, the greatest agreement between modeled SR (Fig. 3; thin gray lines) and observed SR (thin red lines) occurs during the warm season, and the long-term averages (2002-15) of observed SR (dashed red line) fall within the $95 \%$ range of the average computed SR (thick gray lines) during all seasons. We thus conclude that this stochastic model (1) can be used to reliably estimate decadal and multidecadal variability in SR during all seasons, but that estimations of year-to-year variability are primarily limited to the warm season.

\section{b. Identification of changes in climatology of shortwave radiation}

An extended DTR dataset was obtained for 157 locations (Fig. 1b; red circles) during 1956-2015 (Horel et al. 2002). Analogous to the process identified in section 2 , daily station data were binned into $2.5^{\circ}$ latitude and longitude regions, resulting in 15 grid cells over the region (Fig. 1b; blue rectangles). These daily gridded DTR values were used as predictors in Eq. (1) to obtain annual and seasonal SR values (Fig. 4).

The upper $\left(\mathrm{SR}^{97.5}\right)$ and lower $\left(\mathrm{SR}^{2.5}\right)$ bounds about computed average SR during 1956-85 (SR 1$)$ and 1986-2015 $\left(\mathrm{SR}_{2}\right)$ were used to establish significance of departures of the second sample mean from the first (Fig. 4; thick gray lines). Two $t$ distributions were then computed to establish $95 \%$ confidence intervals around the difference in opposite extremes $\left(\mathrm{SR}_{2}^{97.5}-\mathrm{SR}_{1}^{2.5}\right.$ and $\left.\mathrm{SR}_{2}^{2.5}-\mathrm{SR}_{1}^{97.5}\right)$. In other words, the SR values that correspond to the 975th largest sample mean during 1956-85 were compared with SR values that correspond to the 25th largest sample mean during 1986-2015, and $t$ distributions were used to identify $95 \%$ confidence intervals about this difference. The same was done for the 25th largest sample mean during 1956-85 and the 975th largest sample mean during 1986-2015. The largest and smallest values from the two $t$ distribution confidence intervals were used to establish significance of different means between the two climatological periods. This method of establishing statistical significance thus accounts for both model variability (as introduced by $\varepsilon$ ) and interannual variability.

We find that annual SR changed by an average of $-1.8 \%$ or -2.7 [ -4.8 to -0.6$] \mathrm{W} \mathrm{m}^{-2}$ from the period $1956-85$ to 


Modeled SR $-95 \%$ range about model average - Observed SR - - Observed average
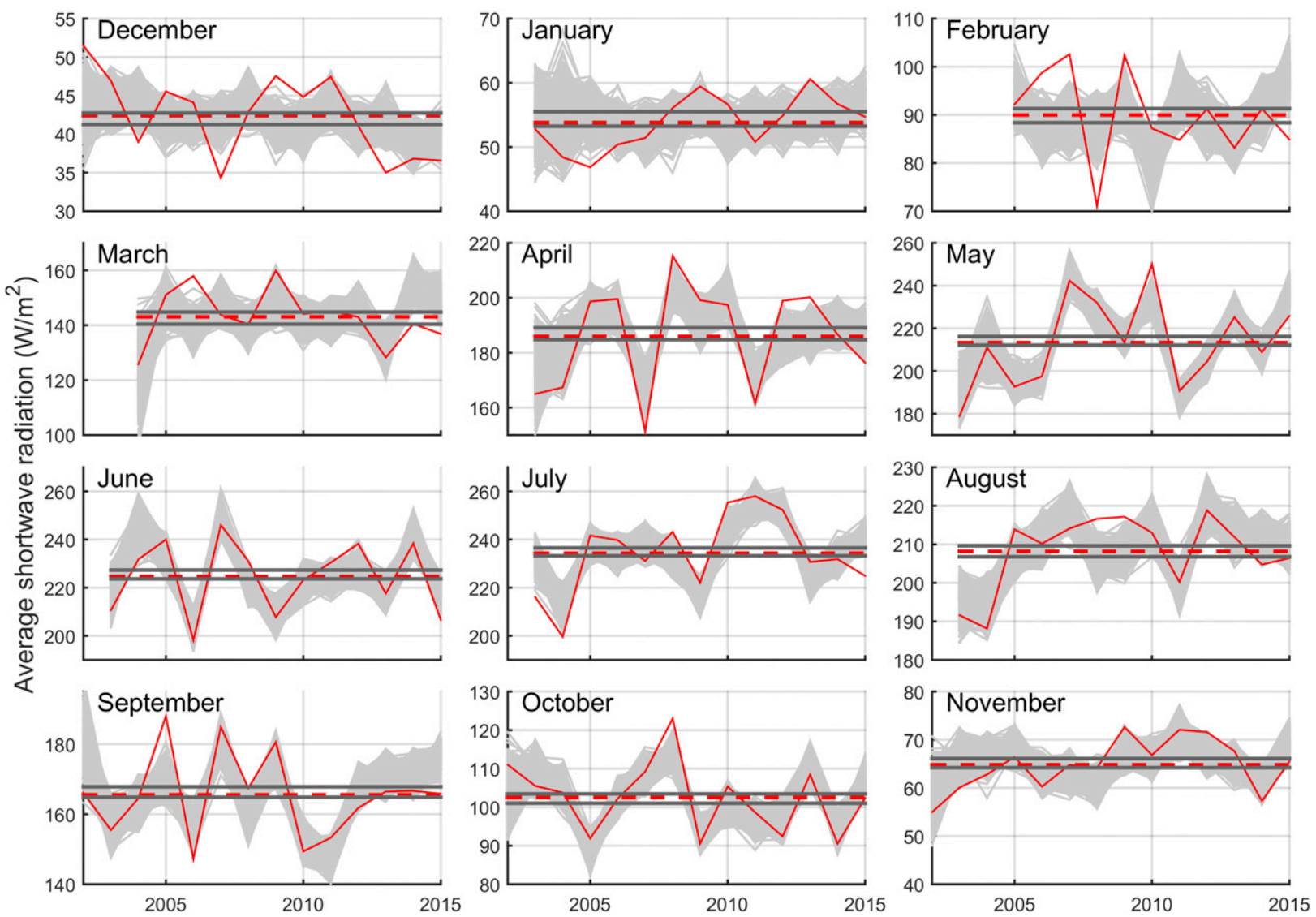

FIG. 3. Comparison of observed annual (thin red line) and long-term average (red dashed line), and computed annual (lightgray lines) and 95\% range about long-term average (thick gray lines) from Eq. (1) of downward shortwave radiation for the northeastern United States.

1986-2015 where the brackets encompass the $95 \%$ confidence bounds about the difference of mean. This decrease is not temporally uniform as the largest shift occurred during the summer when SR changed by an average of $-3.7 \%$ or $-8.4[-14.1$ to -2.5$] \mathrm{W} \mathrm{m}^{-2}$ from the first to the second climatological period. More modest changes of $-2.3[-5.6$ to 0.9$] \mathrm{W} \mathrm{m}^{-2}$ and -0.6 [ -2.5 to 1.3$] \mathrm{W} \mathrm{m}^{-2}$ occurred during fall and winter, respectively, and a slight increase of 0.5 [ -4.2 to 5.0$] \mathrm{W} \mathrm{m}^{-2}$ occurred during spring. However, none of the seasonal changes outside of June-August were deemed statistically significant.

The spatial distributions of changes in SR are illustrated in Fig. 5 (numeric values can be found in Table S2 in the online supplemental material). For this analysis, only grid cells that contained nearly complete climatologies (at least one station with $29 \mathrm{yr}$ of data for each of the two 30-yr periods) were considered, resulting in an analysis of 12 grid cells (as identified in Fig. S1 in the online supplemental material). Confidence intervals for each grid cell were computed analogous to those for the entire region as outlined above. Annual SR generally decreased across the region and many of these changes were deemed statistically significant (filled yellow circles; $p<0.05$ ). Values range from a modest increase (red square) of $0.8 \%\left(1.1 \mathrm{~W} \mathrm{~m}^{-2}\right)$ to a decrease (blue diamond) of $-4.2 \%\left(-6.3 \mathrm{~W} \mathrm{~m}^{-2}\right)$, with most of the SR decreasing between $2 \%$ and $5 \%$ of the $1956-85$ mean. Summer SR decreases occurred across the region, most of which were deemed statistically significant, and ranged from $-0.5 \%\left(-1.3 \mathrm{~W} \mathrm{~m}^{-2}\right)$ to $-6.7 \%\left(-15.6 \mathrm{~W} \mathrm{~m}^{-2}\right)$. During winter, spring, and fall, SR decreased in most regions, however, none of the changes, positive or negative, were deemed significant.

As discussed in section 2, correlations between SR and DTR were relatively weak outside of the warm season, particularly during December-February. As a result, large residual values introduced in (1) as random errors may hide true differences between climatological periods. We thus conclude that annualaverage SR has largely decreased in the northeastern 


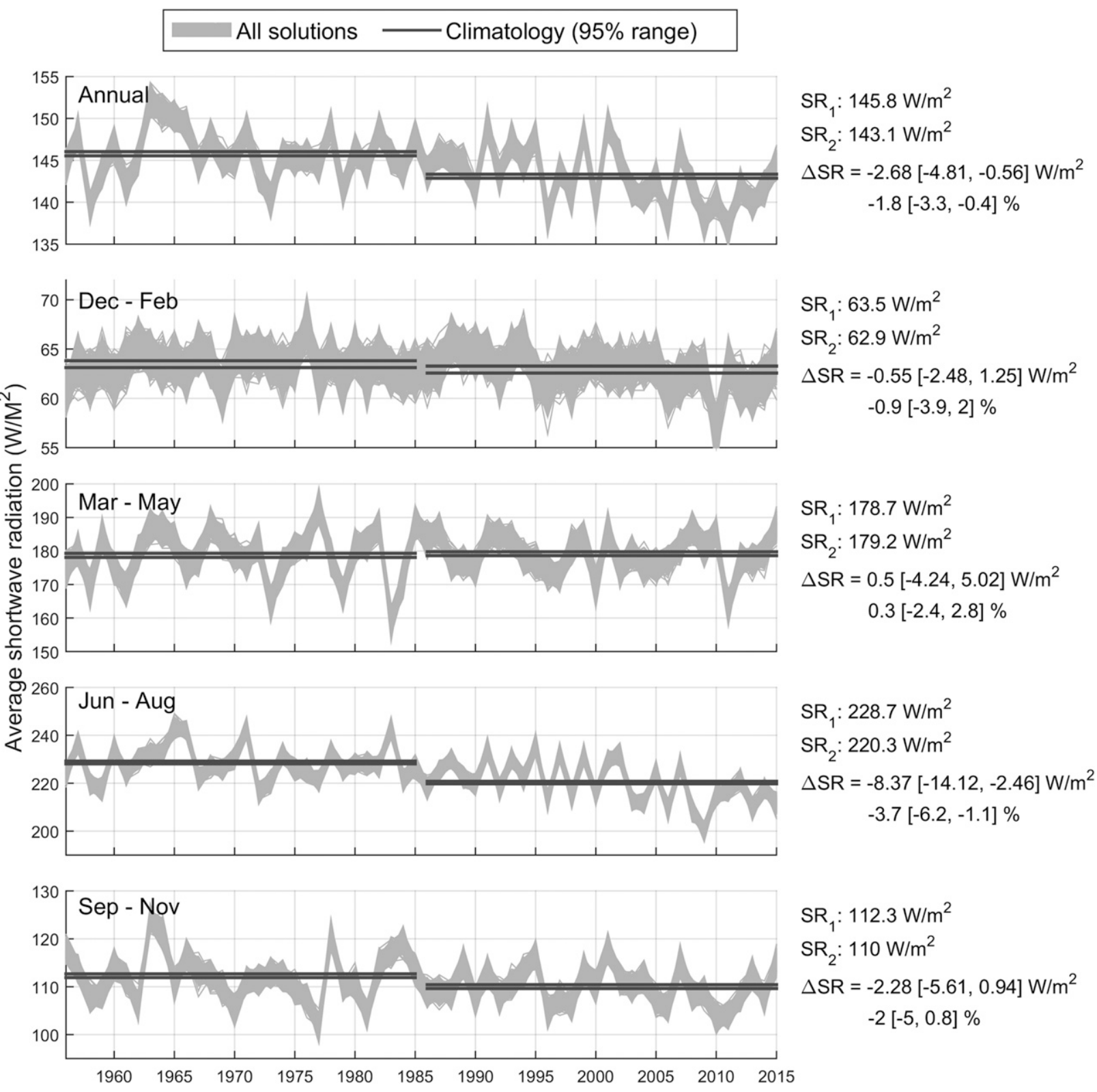

FIG. 4. Computed annual and seasonal downward SR for the northeastern United States (thin gray lines), 95\% range of climatological average values (thick gray lines), and changes in climatological averages $(\Delta \mathrm{SR})$ from $1956-85\left(\mathrm{SR}_{1}\right)$ to $1986-2015\left(\mathrm{SR}_{2}\right)$, where brackets encompass the $95 \%$ confidence bounds about the difference of means.

United States because of decreasing SR during the summer months, but climatological shifts outside of this season cannot be ruled out.

\section{Assessment of spatial and temporal influences on model performance}

\section{a. Geographical influences on model parameters}

To evaluate the extent of key geographical influences on SR and DTR relationships identified here, regression values were recomputed for daily DTR and SR at each of the original 32 stations (Fig. 1a, red circles). The resulting values were plotted against latitude, elevation, and distances to large bodies of water, which were estimated as the shortest linear distance between an observation and the closest Great Lake or the North Atlantic coastline. Because we concluded in section 3 that significant long-term shifts in SR occurred during June-August, results for this season are included in Fig. 6, with lines of best fit (black lines) where individual 

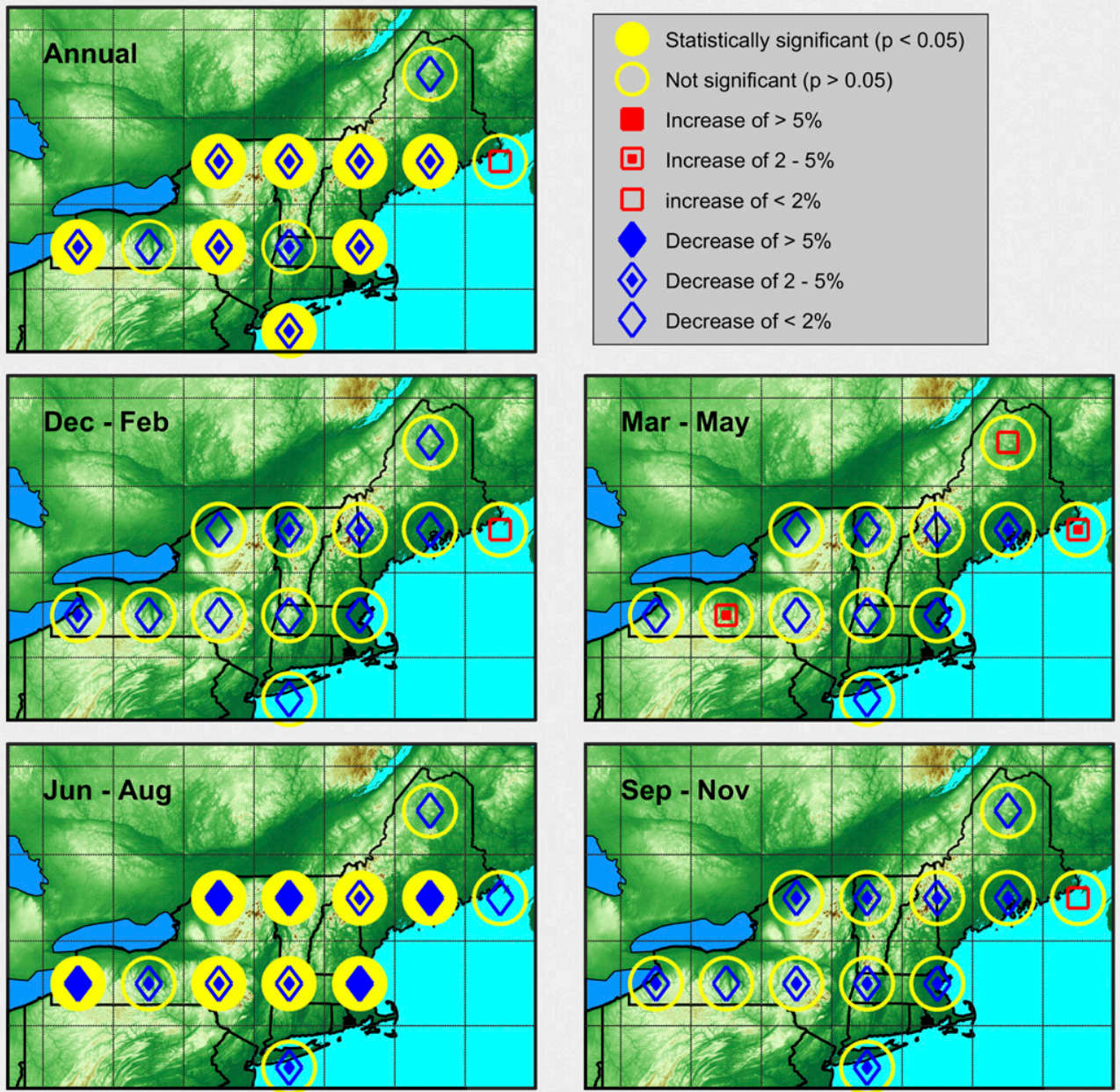

FIG. 5. Annual- and season-average changes in computed downward shortwave radiation from $1956-85\left(\mathrm{SR}_{1}\right)$ to 1986-2015 $\left(\mathrm{SR}_{2}\right)$ for individual grid locations around the northeastern United States. Statistical significance of $\Delta \mathrm{SR}$ $\neq 0$ was established by identifying $95 \%$ confidence intervals that did not encompass zero (filled yellow circles) for increasing (red squares) and decreasing (blue diamonds) SR as computed by Eq. (1). Numeric values can be found in Table S2 in the online supplemental material.

stations are identified by numbers. Results for other seasons are available in Figs. S2-S4 in the online supplemental material.

We find that correlation coefficients between DTR and SR generally increase with station distance to water $(p<0.05)$ during June-August $(r=0.36)$ and SeptemberNovember $(r=0.59)$. We hypothesize that smaller correlations between DTR and SR near large bodies of water likely occur because of a greater influence of horizontal advection on regional temperatures from air originating over water and/or the presence of more atmospheric water vapor, which, because of its large heat capacity, may exhibit a damped diurnal temperature cycle. While large DTRs are usually observed over land during the warm season, diurnal heating can be substantially less within $80 \mathrm{~km}$ of the Great Lakes (Scott and Huff 1996). When only stations farther than $80 \mathrm{~km}$ from large bodies of water are included in the present analysis (Fig. 6; red numbers and thick red lines), this dependence is no longer significant $(p>0.05)$ and even reverses sign during June-August.

The identified dependence of regression values on distance to water within $80 \mathrm{~km}$ must be taken into consideration when evaluating the influence of elevation and latitude, which themselves are dependent on distance to water. Regions that are higher in elevation are less likely to be near water than those that are closer to sea level. Additionally, given the geographical layout of the region under consideration, more southern stations are within $80 \mathrm{~km}$ of the ocean than northern stations (stations within $80 \mathrm{~km}$ of large bodies of water are indicated with light blue concentric circles Fig. 1a). To remove the influence of water on the remaining regression values, the analysis 

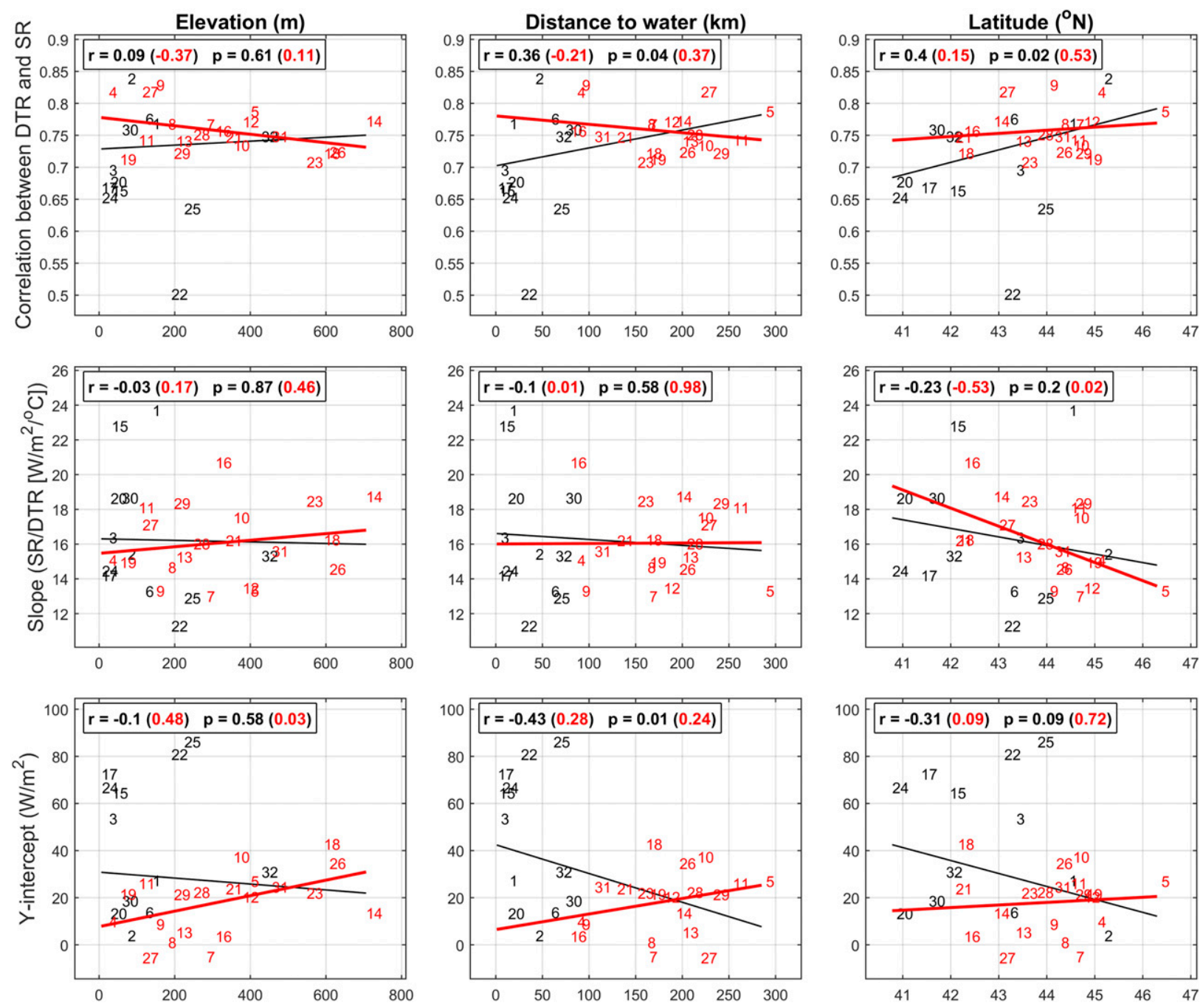

FIG. 6. Examination of geographical influences during June-August including (left) elevation, (center) distance to large bodies of water, and (right) latitude, on individual station SR and DTR regression coefficients, including lines of best fit. Station numbers correspond to those identified in Table S1 in the online supplemental material. Red numbers and lines indicate stations that are at least $80 \mathrm{~km}$ from large bodies of water.

was repeated for elevation and latitude for stations outside of the 80-km buffer regions during June-August and September-November (Fig. 6 and online supplemental Fig. S4; red numbers and thick red lines). Because the distance-to-water dependence was not identified during March-May or December-February $(p>0.05)$, the regression analysis was not repeated during these seasons for the specified stations.

We find that the DTR and SR regression values are largely independent of elevation $(p>0.05)$ up to the highest elevation under consideration here of $700 \mathrm{~m}$, suggesting that the present results are applicable over a wide range of terrain types. There is one notable exception during June-August when elevation appears to have an impact on $y$ intercept values $(r=0.48)$.
Once the stations within buffer regions are removed, we conclude that station latitude does not statistically impact correlation during any of the seasons. We find that slope values are inversely dependent on latitude during all seasons and that this dependence is significant $(p<0.05)$ outside of the $80-\mathrm{km}$ buffer region during June-August, for all locations during December-February. Larger slopes (SR-DTR) are generally observed at the southernmost regions, and smaller slopes at the northernmost regions of the domain. This suggests that for the same change in solar energy input, the DTR response is smaller to the south than it is to the north. The underlying causes for this dependence, and the apparent relationship between elevation and $y$ intercept values during June-August, 

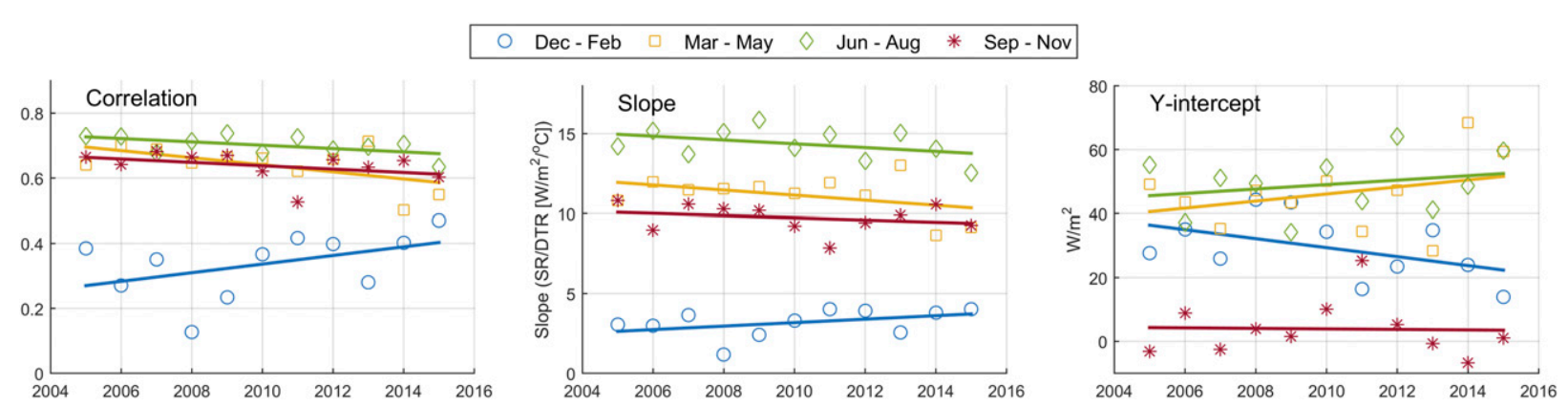

FIG. 7. Seasonal DTR and SR regression values by year with lines of best fit.

are not immediately apparent and a detailed investigation is left for future work.

While some geographical influences have been identified here, the lowest warm-season correlation coefficient between DTR and SR is 0.50 , with the vast majority in excess of 0.70 , all of which are statistically significant at the 99\% level. We conclude that the parameters in Table 1 and subsequent analyses are generally applicable to the entire region. However, one must exercise caution when applying the results to individual locations that are within $80 \mathrm{~km}$ of the Great Lakes or the Atlantic Ocean and/or those that are on the southern or northernmost boundaries of the domain (Fig. 1).

\section{b. Temporal evolution of model parameters}

The findings presented here of decreasing annual SR from one 30-yr period to the next, particularly during the warm season, are the result of decreasing DTR values in Eq. (1). In agreement with these findings, decreasing DTR has been observed in various parts of the world over the past several decades (Karl et al. 1993; Alexander et al. 2006); however, some of the largest decreases have been observed during the cold season (Easterling et al. 1997; Vose et al. 2005). In addition to changing cloud cover, decreasing DTR has been attributed to changes in precipitation (Zhou et al. 2009), soil moisture (Dai et al. 1999), and vegetation (Zhou et al. 2009). Through changes in surface energy balance, Davy et al. (2017) additionally showed that boundary layer depth may modulate surface air temperature, thereby resulting in asymmetrical warming between night and day. The results discussed in present study are thus dependent on the idea that these additional processes do not have an evolving influence on summertime DTR in the northeastern United States and that the DTR-SR relationship is time invariant. Here, we examine the validity of the time invariance assumption in two ways. First, we recompute regression values for DTR and SR through time during the period of available data. Second, we assess the likelihood of significant changes in DTR resulting from other influential factors and examine long-term regional trends in surface solar radiation as identified in the existing literature.

Analogous to the computation of values presented in Table 1 and Fig. 2, regression coefficients were again computed using daily gridded DTR and SR values averaged over the Northeast, but unique values were obtained for each year. The resulting temporal evolution of regression values during 2005-15 for each season is illustrated in Fig. 7. A commonly used nonparametric test for nonstationarity of a time series, the Mann-Kendall test (Wilks 2011), was used to determine if the regression values (correlation, slope, and $y$ intercept) exhibit trends that are statistically significant at the $95 \%$ level. We find that correlations and slopes are generally decreasing for all seasons except winter, and that $y$ intercepts are increasing during March-May and JuneAugust and decreasing during December-February. The null hypothesis of zero change in correlation, slope, or $y$ intercept, however, could not be rejected for any of the seasons. This analysis suggests that other processes (or the sum of such processes) have had a relatively constant influence on DTR over this period. While not statistically significant, we note that the regression trends during winter oppose trends that occur during all other seasons. In particular, correlations are increasing during the winter, suggesting that SR has an increasing influence on DTR during this season and prompting an interesting research question that is left for future work.

The existing literature provides evidence to support our conclusion of a relatively stable DTR-SR relationship through time. We find that long-term variability in cloud cover, and the resulting variability in shortwave radiation at the surface, is likely the dominant driver of long-term DTR changes during the warm season, which encompasses our key results. Dai et al. (1999) and Stone and Weaver (2003) showed that increased cloud cover 
during the day reduces incoming solar radiation thus limiting daytime heating and damping DTR. A longterm increase in summertime cloud cover has been observed in the northeastern United States associated with a positive precipitation trend (Lauritsen and Rogers 2012; Tang and Leng 2013). The latter is of particular importance because soil moisture, which largely depends on precipitation, can further limit daytime heating, therefore reducing summertime DTR through evaporative cooling and increased heat capacity of the soil (Dai et al. 1999; Durre et al. 2000; Zhang et al. 2009; Tang and Leng 2013). Because of the dependence of precipitation, and thus soil moisture, on cloud cover, the response of DTR is amplified. While the strength of this feedback may have varied through time, Lauritsen and Rogers (2012) concluded that changes in cloud cover alone explained $60 \%$ of the DTR decrease in the northeastern United States over the past several decades, while changes in precipitation and soil moisture combined explained less than $20 \%$ of this change. These results are supported by Betts et al. (2016), who concluded that DTR was most strongly dependent on cloud cover during the warm season in recent years in Vermont, and Betts et al. (2015), who identified a similar dependence over a 55 -yr period in the Canadian Prairies. We therefore find that DTR has been strongly dependent on SR during the warm season, and that the model parameters summarized in Table 1 are likely representative of values that would have been derived if longer duration data were available in our area of interest. Importantly, Durre et al. (2000) found that extreme warm temperatures may amplify the daily temperature response to changing cloud cover, suggesting that it may be necessary to recalibrate the present model Eq. (1) when applied to future data.

Liepert (2002) examined decadal changes in surface solar radiation in the United States using data obtained from the 1961-90 United States National Solar Radiation Database (NSRDB). She identified an average decrease in surface radiation of $10 \%$ in the United States during this time, which is in agreement with the timing of decreases in many regions of the world (Ohmura 2009; Wild 2012). This was followed by a period of global brightening that began around 1985 (Wild 2012). Because such trends appear to be in contrast to those identified here, a brief discussion is warranted. As illustrated in Fig. 4, we note an average decrease of modeled SR during June-August 1961-90 of about 3\%. Following the work of Liepert (2002), we obtained solar radiation data from the NSRDB (rredc.nrel.gov/solar/old_data/ $\mathrm{nsrdb} /$ ) for six locations around the northeastern United States during 1961-90. During June-August, only two locations (Concord, New Hampshire, and Caribou, Maine) exhibited decreases, both of which were less than $5 \%$, while the other four locations (Albany and Buffalo, New York; Burlington, Vermont; and Bridgeport, Connecticut) all exhibited increases of less than $5 \%$. To examine the period of global brightening, we obtained data from the updated NSRDB during 1991-2010. Data for the same six stations were examined and again revealed contradicting trends, all of which resulted in a radiation change of less than $4 \%$. As a final verification of the methods discussed in the present study, we find that the average modeled summertime SR values are well correlated with the average radiation values obtained from NSRDB $(r=0.76$ during both time periods). We thus conclude that the results presented here do not contradict the existing literature with respect to global dimming and brightening, but instead that regional and seasonal signatures deviate from those obtained by analyses of global and annual datasets.

\section{Summary and conclusions}

Investments in large-scale PV projects are at risk when long-term weather patterns unexpectedly change (IFC 2014) such as climatological shifts in cloud cover (Dai et al. 1999; Jones and Underwood 2001; IPCC 2011). In the northeastern United States, where aggressive renewable energy goals have been identified (Durkay 2016), long-term precipitation and cloud cover have been changing and are expected to be further modified under global climate change (Liepert 2002; Peterson et al. 2013; Walsh et al. 2014). In spite of this, observed shortwave radiation data that are used for long-term estimates of energy production at prospective utility-scale PV sites usually span periods of a decade or less (IFC 2014), and detailed solar and weather data have only been measured near solar arrays during recent years (Betts et al. 2016).

Expanding upon results by Betts et al. $(2013,2014)$ and Betts and Tawfik (2016), here we use a simple linear regression model with diurnal temperature range as a predictor to compute a climatology of shortwave radiation for the northeastern United States. The resulting values during two successive 30-yr periods, 1956-85 and 1986-2015, were examined to identify changes in annual and seasonal shortwave radiation. We conclude that annual shortwave radiation has changed by about $-1.8 \%$ or $-2.7[-4.8$ to -0.6$] \mathrm{W} \mathrm{m}^{-2}$, where the brackets encompass the $95 \%$ confidence bounds about the difference of mean. This annual change is primarily due to a decrease in incoming shortwave radiation during the summer months of $3.7 \%$ or $-8.4[-14.1$ to -2.5$] \mathrm{Wm}^{-2}$. These decreases in SR occurred throughout the northeastern United States with 
summer decreases in excess of $6 \%\left(>15 \mathrm{~W} \mathrm{~m}^{-2}\right)$ in some regions.

While these results may be applied to the entire northeastern United States and its subregions, it should be noted that geographical features, such as distance to large bodies of water, must be taken into consideration with localized planning. The annual decrease in shortwave radiation identified here is a function of decreasing DTR resulting from increasing cloud cover over much of the United States (Dai et al. 1999, 2006; Stone and Weaver 2003), which corresponds to observed increases in precipitation around the region (Lauritsen and Rogers 2012; Hartmann et al. 2013; Tang and Leng 2013; Peterson et al. 2013; Walsh et al. 2014). The latter may amplify the SRDTR relationship because increased soil moisture can reduce daytime heating through latent effects (Dai et al. 1999; Durre et al. 2000; Zhang et al. 2009; Tang and Leng 2013; Lauritsen and Rogers 2012) particularly under extremely warm conditions (Durre et al. 2000), thus suggesting that the model parameters identified here may need adjustment when applied to future data. Importantly, while changing cloud cover is the dominant driver of changes in DTR during the warm season, this is not the case during the cold season (Betts and Tawfik 2016), as indicated in the present study (Table 1) by lower correlation coefficients and higher relative errors. The lack of statistical significance surrounding long-term changes in SR during nonsummer seasons should not suggest that such changes are not happening but instead that other methods must be used to identify them.

Regional precipitation and associated cloud cover is expected to be modified around the globe under climate change, but the underlying physical mechanisms are varied (Trenberth et al. 2003; Screen and Simmonds 2014; Meehl et al. 2005). Modeling studies indicate that precipitation will continue to increase in the northeastern United States, but this is primarily the case during winter and spring (Walsh et al. 2014). The present analysis instead suggests decreasing shortwave radiation during the summer months. Because this coincides with the season of greatest insolation and the highest potential for energy production, financial implications may be large for the solar energy industry if such trends persist into the future, thus underscoring the need to obtain a more complete picture of the underlying processes. It is of interest to note that the Great Lakes, which are directly upwind of the region under consideration for the present study, have been warming at an unprecedented rate during the summer months (Austin and Coleman 2008; Zhong et al. 2016), consistent with the behavior of inland waters worldwide in response to climate change (O'Reilly et al. 2015). Because the lakes have been warming faster than the overlying air, evaporation rates have also substantially increased during the warm season (Hanrahan et al. 2010). It thus follows that higher moisture content would be found in regions downwind of the Great Lakes during the summer, potentially resulting in greater cloud cover, consistent with the present findings.

The shortwave radiation estimates presented here provide necessary information about climatological changes in downward near-surface shortwave radiation in the northeastern United States. We conclude that it has been decreasing over much of this region, particularly during the summer months. While beyond the scope of this work, these methods may also be used to validate and/or correct satellite data, which tend to overestimate surface shortwave radiation (Zhang et al. 2015), and climate models, which tend to underestimate long-term variability (Wild and Schmucki 2011), thus improving confidence in future simulations. A possible extension of this work might address the seasonal dependence of regression coefficients identified here; the analysis may be repeated by computing SR as a fraction of daily solar irradiance at the top of the atmosphere, thus allowing for a direct comparison between transmissivity and DTR. As more data are collected in the upcoming years, this work may also be combined with detailed SR data paired with measured electrical power production at solar farms (Betts et al. 2016) to directly estimate how solar power potential is changing through time under climate change.

Acknowledgments. This work was supported by the Vermont Low Income Trust for Electricity (VLITE) and the National Science Foundation through VT EPSCoR (Award 1556770). This research was made possible in part because of data made available by the governmental agencies, commercial firms, and educational institutions participating in MesoWest. The authors thank Dr. Alan Betts for productive conversations and helpful feedback, Jason Kaiser for his technical assistance, and three anonymous reviewers for valuable feedback and suggestions.

\section{REFERENCES}

Ahrens, D. C., 2013: Meteorology Today. 10th ed. Brooks/Cole, $569 \mathrm{pp}$.

Alexander, L. V., and Coauthors, 2006: Global observed changes in daily climate extremes of temperature and precipitation. J. Geophys. Res., 111, D05109, doi:10.1029/2005JD006290.

Andres, R. J., and Coauthors, 2012: A synthesis of carbon dioxide emissions from fossil-fuel combustion. Biogeosciences, 9, 1845-1871, doi:10.5194/bg-9-1845-2012.

Austin, J., and S. Coleman, 2008: A century of temperature variability in Lake Superior. Limnol. Oceanogr., 53, 2724-2730, doi:10.4319/lo.2008.53.6.2724.

Betts, A. K., and A. B. Tawfik, 2016: Annual climatology of the diurnal cycle on the Canadian Prairies. Front. Earth Sci., 4, doi:10.3389/feart.2016.00001. 
- R. Desjardins, and D. Worth, 2013: Cloud radiative forcing of the diurnal cycle climate of the Canadian Prairies. J. Geophys. Res. Atmos., 118, 8935-8953, doi:10.1002/jgrd.50593.

,,--- , and B. Beckage, 2014: Climate coupling between temperature, humidity, precipitation and cloud cover over the Canadian Prairies. J. Geophys. Res. Atmos., 119, $13305-$ 13 326, doi:10.1002/2014JD022511.

,$- \ldots$, A. C. M. Beljaars, and A. Tawfik, 2015: Observational study of land-surface-cloud-atmosphere coupling on daily timescales. Front. Earth Sci., 3, doi:10.3389/feart.2015.00013.

- J. Hamilton, S. Ligon, and A. M. Mahar, 2016: Integrating solar energy and climate research into science education. Earth's Future, 4, 2-13, doi:10.1002/2015EF000315.

Canadell, J. G., and Coauthors, 2007: Contributions to accelerating atmospheric $\mathrm{CO}_{2}$ growth from economic activity, carbon intensity, and efficiency of natural sinks. Proc. Natl. Acad. Sci. USA, 104, 18 866-18 870, doi:10.1073/pnas.0702737104.

Da Costa, E. D., and A. C. De Verdiere, 2002: The 7.7-year North Atlantic Oscillation. Quart. J. Roy. Meteor. Soc., 128, 797-817, doi:10.1256/0035900021643692.

Dai, A., K. E. Trenberth, and T. R. Karl, 1999: Effects of clouds, soil moisture, precipitation, and water vapor on diurnal temperature range. J. Climate, 12, 2451-2473, doi:10.1175/ 1520-0442(1999)012<2451:EOCSMP >2.0.CO;2.

— T. R. Karl, B. Sun, and K. E. Trenberth, 2006: Recent trends in cloudiness over the United States: A tale of monitoring inadequacies. Bull. Amer. Meteor. Soc., 87, 597-606, doi:10.1175/BAMS-87-5-597.

Davy, R., I. Esau, A. Chernokulsky, S. Outten, and S. Zilitinkevich, 2017: Diurnal asymmetry to the observed global warming. Int. J. Climatol., 37, 79-93, doi:10.1002/joc.4688.

Dim, J. R., H. Murakami, T. Y. Nakajima, B. Nordell, A. K. Heidinger, and T. Takamura, 2011: The recent state of the climate: Driving components of cloud-type variability. J. Geophys. Res., 116, D11117, doi:10.1029/2010JD014559.

Durkay, J., 2016: State renewable portfolio standards and goals. National Conference of State Legislatures, accessed 13 December 2016, http://www.ncsl.org/research/energy/ renewable-portfolio-standards.aspx.

Durre, I., J. M. Wallace, and D. P. Lettenmaier, 2000: Dependence of extreme daily maximum temperatures on antecedent soil moisture in the contiguous United States during summer. J. Climate, 13, 2641-2651, doi:10.1175/ 1520-0442(2000)013<2641:DOEDMT>2.0.CO;2.

Easterling, D. R., and Coauthors, 1997: Maximum and minimum temperature trends for the globe. Science, 277, 364-367, doi:10.1126/science.277.5324.364.

Eastman, R., and S. G. Warren, 2013: A 39-yr survey of cloud change from land stations worldwide 1971-2009: Long-term trends, relation to aerosols, and expansion of the tropical belt. J. Climate, 26, 1286-1303, doi:10.1175/JCLI-D-12-00280.1.

Hanrahan, J. L., S. V. Kravtsov, and P. J. Roebber, 2009: Quasiperiodic decadal cycles in levels of Lakes Michigan and Huron. J. Great Lakes Res., 35, 30-35, doi:10.1016/j.jglr.2008.11.004.

,$- \ldots$, and $—, 2010$ : Connecting past and present climate variability to the water levels of Lakes Michigan and Huron. Geophys. Res. Lett., 37, L01701, doi:10.1029/2009GL041707.

- P. Roebber, and S. Kravtsov, 2014: attribution of decadalscale lake-level trends in the Michigan-Huron system. Water, 6, 2278-2299, doi:10.3390/w6082278.

Hartmann, D. L., and Coauthors, 2013: Observations: Atmosphere and surface. Climate Change 2013: The Physical Science Basis, T. F. Stocker et al., Eds., Cambridge University Press, 159-254.
Honeyman, C., and Coauthors, 2016: U.S. solar market insight executive summary Q4 2016. Solar Energy Industries Association, $20 \mathrm{pp}$.

Horel, J., and Coauthors, 2002: Mesowest: Cooperative mesonets in the western United States. Bull. Amer. Meteor. Soc., 83, 211-225, doi:10.1175/1520-0477(2002)083<0211:MCMITW > 2.3.CO;2.

IFC, 2014: Utility-scale photovoltaic power plants: A project developer's guide. $216 \mathrm{pp}$. , http://www.ifc.org/ wps/wcm/connect/f05d3e00498e0841bb6fbbe54d141794/ IFC+Solar+ Report_Web+_08+05.pdf?MOD=AJPERES.

IPCC, 2011: Summary for policymakers. Renewable Energy Sources and Climate Change Mitigation, O. Edenhofer et al., Eds., Cambridge University Press, 246 pp., http://www.ipcc.ch/pdf/ special-reports/srren/SRREN_FD_SPM_final.pdf.

Jackson, L. S., and P. M. Forster, 2010: An empirical study of geographic and seasonal variations in diurnal temperature range. J. Climate, 23, 3205-3221, doi:10.1175/2010JCLI3215.1.

Jones, A. D., and C. P. Underwood, 2001: A thermal model for photovoltaic systems. Sol. Energy, 70, 349-359, doi:10.1016/ S0038-092X(00)00149-3.

Karl, T. R., and Coauthors, 1993: A new perspective on recent global warming: Asymmetric trends of daily maximum and minimum temperature. Bull. Amer. Meteor. Soc., 74, 1007-1023, doi:10.1175/1520-0477(1993)074<1007:ANPORG>2.0.CO;2.

Lauritsen, R. G., and J. C. Rogers, 2012: U.S. diurnal temperature range variability and regional causal mechanisms, 1901-2002. J. Climate, 25, 7216-7231, doi:10.1175/JCLI-D-11-00429.1.

Le Quéré, C., and Coauthors, 2009: Trends in the sources and sinks of carbon dioxide. Nat. Geosci., 2, 831-836, doi:10.1038/ngeo689.

Liepert, B. G., 2002: Observed reductions of surface solar radiation at sites in the United States and worldwide from 1961 to 1990. J. Geophys. Res., 29, 1-4, doi:10.1029/2002GL014910.

Meehl, G. A., J. M. Arblaster, and C. Tebaldi, 2005: Understanding future patterns of increased precipitation intensity in climate model simulations. Geophys. Res. Lett., 32, L18719, doi:10.1029/2005GL023680.

Moron, V., R. Vautard, and M. Ghil, 1998: Trends, interdecadal and interannual oscillations in global sea-surface temperatures. Climate Dyn., 14, 545-496, doi:10.1007/s003820050241.

Ohmura, A., 2009: Observed decadal variations in surface solar radiation and their causes. J. Geophys. Res., 114, D00D05, doi:10.1029/2008JD011290.

O'Reilly, C. M., and Coauthors, 2015: Rapid and highly variable warming of lake surface waters around the globe. Geophys. Res. Lett., 42, 10 773-10 781, doi:10.1002/2015GL066235.

Peterson, T. C., and Coauthors, 2013: Monitoring and understanding changes in heat waves, cold waves, floods, and droughts in the United States. Bull. Amer. Meteor. Soc., 94, 821-834, doi:10.1175/BAMS-D-12-00066.1.

Scott, R. W., and F. A. Huff, 1996: Impacts of the Great Lakes on regional climate conditions. J. Great Lakes Res., 22, 845-863, doi:10.1016/S0380-1330(96)71006-7.

Screen, J. A., and I. Simmonds, 2014: Amplified mid-latitude planetary waves favour particular regional weather extremes. Nat. Climate Change, 4, 704-709, doi:10.1038/nclimate2271.

Shmalensee, R., and Coauthors, 2015: The Future of Solar Energy. Massachusetts Institute of Technology, 356 pp., http://energy.mit.edu/wp-content/uploads/2015/05/MITEIThe-Future-of-Solar-Energy.pdf.

Stone, D., and A. Weaver, 2003: Factors contributing to diurnal temperature range trends in twentieth and twenty-first century simulations of the CCCma coupled model. Climate Dyn., 20, 435-445, doi:10.1007/s00382-002-0288-y. 
Tang, Q., and G. Leng, 2013: Changes in cloud cover, precipitation, and summer temperature in North America from 1982 to 2009. J. Climate, 26, 1733-1744, doi:10.1175/JCLI-D-12-00225.1.

Trenberth, K. E., A. Dai, R. M. Rasmussen, and D. B. Parsons, 2003: The changing character of precipitation. Bull. Amer. Meteor. Soc., 84, 1205-1217, doi:10.1175/BAMS-84-9-1205.

Vose, R. S., D. R. Easterling, and B. Gleason, 2005: Maximum and minimum temperature trends for the globe: An update through 2004. Geophys. Res. Lett., 32, L23822, doi:10.1029/2005GL024379.

Walsh, J., and Coauthors, 2014: Precipitation change. Climate Change Impacts in the United States, National Climate Assessment, 19-67, http://nca2014.globalchange.gov/report/ our-changing-climate/precipitation-change.

Wild, M., 2012: Enlightening global dimming and brightening. Bull. Amer. Meteor. Soc., 93, 27-37, doi:10.1175/BAMS-D-11-00074.1. and E. Schmucki, 2011: Assessment of global dimming and brightening in IPCC- $\mathrm{AR}_{4} / \mathrm{CIMP}_{3}$ models and $\mathrm{ERA}_{40}$. Climate Dyn., 37, 1671-1688, doi:10.1007/s00382-010-0939-3.
Wilks, D., 2011: Statistical Methods in the Atmospheric Sciences. 3rd ed. Academic Press, 704 pp.

Zhang, J., W. C. Wang, and L. Wu, 2009: Land-atmosphere coupling and diurnal temperature range over the contiguous United States. Geophys. Res. Lett., 36, L06706, doi:10.1029/2009GL037505.

Zhang, X., S. Liang., M. Wild, and B. Jiang, 2015: Analysis of surface incident shortwave radiation from four satellite products. Remote Sens. Environ., 165, 186-202, doi:10.1016/ j.rse.2015.05.015.

Zhong, Y., M. Notaro, S. J. Vavrus, and M. J. Foster, 2016: Recent accelerated warming of the Laurentian Great Lakes: Physical drivers. Limnol. Oceanogr., 61, 1762-1786, doi:10.1002/ lno.10331.

Zhou, L., A. Dai, Y. Dai, R. S. Vose, C.-Z. Zou, Y. Tian, and H. Chen, 2009: Spatial dependence of diurnal temperature range trends on precipitation from 1950 to 2004. Climate Dyn., 32, 429-440, doi:10.1007/s00382-008-0387-5. 